\title{
Pharmacologic Treatment of Eosinophilic Esophagitis
}

\author{
Alex Straumann, $M D^{*}$ \\ Ekaterina Safroneeva, PhD
}

\author{
Address \\ *Swiss EoE Clinic and EoE Research Network, Roemerstrasse 7, 4600, Olten, \\ Switzerland \\ Email: alex.straumann@hin.ch
}

Published online: 8 April 2015

(C) Springer International Publishing AG 2015

This article is part of the Topical Collection on Food Allergy

Keywords Eosinophilic esophagitis - Natural history - Esophageal remodeling · Food impaction - Indications for treatment · Corticosteroids - Immunosuppressants · Biologic therapy $\cdot$ Unmet needs

\section{Opinion statement}

Eosinophilic esophagitis ( $\mathrm{EOE})$ is an immune-mediated, chronic inflammatory disease of the esophagus. If left untreated, eosinophilic inflammation induces esophageal remodeling with fibrosis and stricture formation, and patients are permanently at risk of experiencing food impactions. Therefore, it is widely accepted that active EoE should be treated. An ideal EoE therapy should achieve two therapeutic goals: first, to resolve symptoms and, second, to control inflammation. Avoidance of food allergens by the means of food elimination diets as well as anti-inflammatory drugs has the ability to achieve both of these goals. Among the pharmacologic options, only corticosteroids have documented efficacy, whereas alternatives have shown rather disappointing results or are still under evaluation. Swallowed topical corticosteroids (TCS) are at least as efficient as systemically administered corticosteroids (SCS) and have fewer side effects. As such, TCS are widely used as a first-line drug in the treatment of EoE, even though this compound is not approved for this indication by regulatory authorities. Unfortunately, the therapeutic goals cannot be achieved in approximately $30 \%$ of EoE patients, despite appropriate treatment with corticosteroids. For this "difficult-to-treat" patient category, therapeutic alternatives are urgently needed.

Key points

1. Clinically and histologically active eosinophilic esophagitis must be treated, even when patients effectively cope with their symptoms.

2. Swallowed topical corticosteroids have proven efficacy, a good safety profile and are currently used as a first-line pharmacologic treatment of eosinophilic esophagitis. 
3. Eosinophilic esophagitis is a chronic disease; as such, a long-term follow-up and therapeutic strategy is needed.

\section{Introduction}

Eosinophilic esophagitis (EoE), a clinicopathologically characterized syndrome, was first recognized and described in the early 1990 s $[1 \bullet, 2]$. Dysphagia and food impaction are the typical manifestations in adults, whereas in children, food refusal and failure to thrive are the predominant symptoms [3-5]. EoE was originally regarded as something of a curiosity. However, due to increasing incidence of EoE in westernized countries $[6,7]$, it has now reached a prevalence comparable to that of Crohn's disease and is likely to be the most common cause of both dysphagia resulting from ingestion of solid food and spontaneous perforation of the esophagus [6]. Two decades of intense research has uncovered many molecular, immunological, and clinical aspects of this chronic inflammatory disorder. In this article, we will focus entirely on the pharmacologic treatment of EoE, in particular on indications for treatment, therapeutic goals, the currently available options, and the practical pharmacotherapy.

\section{Indications for treatment of eosinophilic esophagitis}

When a scientific community is confronted with a new disease, the understanding of its natural course is crucial before any treatment modality can be considered. The first natural history study has demonstrated that EoE is a chronic disease and that symptoms and inflammation persist over the years [8]. As such, the quality of life of EoE patients is substantially impaired as long as EoE is not properly treated [3-5].

Basic science research and clinical studies have accordingly confirmed that an ongoing active eosinophilic esophageal inflammation leads to deposition of subepithelial fibrous tissue in the esophageal wall [9-11]. This so-called "remodeling" induces alterations that finally result in a rigid and fragile esophagus with impaired function [3-5]. It is well documented that this process can be prevented or even reversed by an anti-eosinophil treatment $[11,12 \bullet \bullet]$.

EoE patients frequently experience long-lasting food impactions that necessitate endoscopic interventions [13]. This complication harbors a relevant risk for esophageal injury. A recently published retrospective observational study has shown that patients treated with an antieosinophil treatment experienced a significant lower number of food

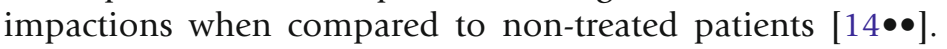

In summary, clinically and histologically active EoE should be treated with anti-eosinophil medication because this measure has potential: first, to diminish symptoms and to improve therefore the quality of life of EoE patients; second, to prevent esophageal damage caused by tissue remodeling due to unbridled eosinophilic inflammation; and third, to reduce the risk of severe esophageal injury by preventing long-lasting food impactions. 


\section{Treatment goals in eosinophilic esophagitis}

At present, the target of EoE treatment is still a subject of much debate. Should the treatment result in the improvement of symptoms or biologic measures or both? In general, the decision to target the treatment on symptoms, biologic measures or the combination of the two strongly depends on the impact of the disease-inherent alterations on the symptoms and availability of suitable biologic measures (e.g., biomarkers) that can be used as indicators of disease severity and/or organ damage. The stronger the relationship between a particular biologic measure and organ damage is, the more critical it is to assess such a biologic measure [15]. It is evident that resolution of symptoms is the first goal of EoE treatment. However, given the fact the ongoing eosinophilic inflammation in EoE results in a long-term organ damage, bringing eosinophilic inflammation under control has to be likely regarded as the second therapeutic goal.

In conclusion, the ideal pharmacological intervention in EoE has to improve symptoms and to reduce inflammation.

\section{General principles of pharmacological EoE-treatment}

Eosinophilic esophagitis is a young disease, and experience with medical treatment is therefore still limited. Those pharmacologic therapies that have already been evaluated for the purposes of EoE management will now be discussed.

\section{Proton-pump inhibitors}

Currently, proton-pump inhibitors (PPI) are used in EoE patients with coexisting gastroesophageal reflux disease (GERD) [4]. Given the high prevalence of GERD in a general population, it is likely that both diseases can cooccur. However, it is also possible that impairment of the lower esophageal sphincter may lead to gastroesophageal reflux as a sequela of EoE [16]. Moreover, it is also known that acid exposure in EoE subjects is more painful than in control patients [17]. As such, the use of PPI may improve symptoms, such as pain, but may in general not have an effect on the underlying inflammatory process.

However, meanwhile, we have learned that a subset of patients with EoE responds to treatment with PPI [18], and this clinical observation has been confirmed in a prospective trial, demonstrating that half of patients with a typical EoE presentation respond to PPI treatment $[19 \bullet \bullet$. This so called "PPI-responsive esophageal eosinophilia" is characterized by symptoms, endoscopic, histologic, and even transcriptional abnormalities comparable with "classic" EoE but responding to 
monotherapy with PPI $[4,17,20]$. However, it remains to be determined whether acid suppression in patients diagnosed with PPIresponsive esophageal eosinophilia can be considered as a long-term therapeutic option, and further studies are needed before PPI can be included in the definitive armamentarium of therapies for the management of EoE.

\section{Corticosteroids}

The first study demonstrating that corticosteroids are able to bring active EoE into remission was published in 1998. Children with marked esophageal eosinophilia and chronic reflux-like symptoms unresponsive to aggressive medical anti-reflux therapy were treated with methylprednisolone [21]. After corticosteroid therapy, all but one patient had dramatic clinical and histological improvement. Shortly afterwards, it was demonstrated that EoE responded even to treatment with topically administered corticosteroids [22]. In 2008, an important prospective controlled trial comparing oral prednisone with swallowed topical fluticasone was published [23]. Following 4 weeks of therapy, topical fluticasone was as effective as systemic corticosteroids in bringing EoE patients into remission. However, treatment with swallowed topical fluticasone had fewer side effects. This study provided the first strong evidence that EoE can be controlled without the use of systemic corticosteroids. A number of controlled clinical trials in adult and pediatric EoE have demonstrated that swallowed corticosteroids (budesonide, fluticasone, and ciclesonide) deposited on the esophageal surface are highly effective in resolving symptoms and endoscopic and histologic alteration of EoE [24-27]. Overall, the response rates to treatment with swallowed topical corticosteroids were between 50 and $87 \%$ [4]. The main drawback of systemic and topical corticosteroid treatment is that almost all patients relapse rapidly after cessation of therapy $[23,28]$. Therefore, corticosteroids are able to control, but not to cure, EoE. The main side effect of swallowed topical corticosteroids is infection of the oropharyngeal cavity or the esophagus with Candida albicans [4]. If necessary, this infection can easily be treated with topically administered antifungal drugs. Fortunately, systemic side effects of the swallowed topical corticosteroids occur but rarely. However, it is still prudent to exercise caution, when treating children and adults with high doses of swallowed topical corticosteroids.

Since EoE is a chronic disease, a long-term therapeutic management strategy is required. In a first controlled long-term study, adult EoE patients were treated for 1 year with low-dose budesonide [28]. The treatment was effective in keeping $50 \%$ of patients in complete or partial histologic remission, whereas none of the placebo patients was in remission at the end of the study period. However, the optimal maintenance regimen has not yet been determined, and further studies are necessary to evaluate the optimal dose of swallowed topical corticosteroids for maintenance therapy.

\section{Leukotriene inhibitors}

An open label study showed that montelukast is able to induce symptomatic relief in adult patients with EoE. However, its use has not been shown to have 


\section{Immunosuppressants}

any effect on esophageal eosinophilia [29]. Unfortunately, neither this symptom relief nor the anti-inflammatory effect could later on be confirmed in a prospective trial of this medication [30]. Therefore, the use of leukotriene inhibitors for treatment of EoE is not recommended [4].

\section{Prostaglandin $\mathrm{D}_{2}$ receptor 2 antagonist}

EoE has many characteristics of a $\mathrm{T}_{\mathrm{H}} 2$ type inflammatory response [32]. Prostaglandin $\mathrm{D}_{2}$ receptor 2 (CRTH2) is a chemoattractant receptor expressed by eosinophils and $\mathrm{T}_{\mathrm{H}} 2$ cells. OC000459 is a first-generation selective prostaglandin $\mathrm{D}_{2}$ receptor 2 antagonist that blocks the ability of prostaglandin $\mathrm{D}_{2}$ to recruit and activate eosinophils and $\mathrm{T}_{\mathrm{H}} 2$ cells. The efficacy and safety of OC000459 monotherapy were evaluated in adult patients with active EoE. An 8 -week treatment with this compound led to a reduction of the eosinophil load in the esophageal tissue by approximately $36 \%$ [33]. EoE-related symptoms improved, and the appearance of EoE-associated endoscopic alterations was diminished. These findings demonstrate that patients with EoE respond to treatment with OC000459. The drug had an excellent safety profile. However, the overall effect was only moderate. The value of a CRTH2 blockade in the treatment of EoE needs to be further evaluated, preferably with new generation compounds.

\section{Biologic agents}

Interleukin 5 (IL-5) is critically important in the maturation, differentiation, activation, and tissue recruitment of eosinophils [34]. Humanized anti-IL-5 antibodies are therefore highly specific anti-eosinophil drugs. One trial performed with anti-IL-5 monoclonal antibodies in adult and two in pediatric EoE have demonstrated a significant reduction of eosinophils in the esophageal tissue and in the peripheral blood [36-38]. Unfortunately, mepolizumab as well as reslizumab exerted only minimal clinical improvement in all three studies [35-37].

In active EoE, the pro-inflammatory cytokine tumor necrosis factor $\alpha$ (TNF- $\alpha$ ) is upregulated and highly expressed in the squamous epithelium [38]. Unfortunately, a proof of concept treatment with the anti-TNF monoclonal antibody infliximab had neither been proven to be effective in reducing eosinophilic tissue infiltration nor in improving EoE-related symptoms [38].

More than $70 \%$ of EoE patients have markedly increased total immunoglobulin E (IgE) serum levels [4]. In addition, the number of IgE+ cells-most 
likely mast cells-in esophageal epithelium is increased in the esophageal mucosa of patients with active EoE [4, 32]. Therefore, it was tempting to evaluate the efficacy of IgE-blocking agents. One prospective, randomized, placebo-controlled trial with omalizumab evaluated the effect of an IgE blockade in 30 adults with eosinophilic esophagitis [39]. Unfortunately,

omalizumab did not reduce EoE-attributed symptoms or tissue eosinophil counts when compared with placebo. Of note, another non-blinded study showed that tissue eosinophils, as well as tryptase- and IgE-positive cells decreased after a 12-week treatment with omalizumab. In addition, endoscopy and symptom scores improved significantly [40]. However, given the design limitation of the second study and the fact, that IgE likely does not play a key role in the immune pathogenesis of EoE [39], the blocking of IgE does not appear to be a very promising approach.

It has been demonstrated that $I L-13$ is a major regulator of the pathways involved in EoE [41]. In a recently published, double-blind, placebo-controlled trial using QAX576, the effect of an IL-13 blocking approach was evaluated in adult patients with active EoE [42]. After a 12-week course of treatment with intravenous QAX576, the eosinophil load decreased by $60 \%$, whereas an increase of $23.3 \%$ was observed in the placebo group.

In conclusion, among the already evaluated biologic agents, anti-IL-13 monoclonal antibody holds most promise as a novel therapeutic approach for management of EoE.

\section{Pharmacological EoE treatment in clinical practice}

Following a discussion of currently available options for the pharmacological treatment of EoE, we would like to discuss the way these therapies can be used in a routine clinical practice.

Once a clinician is confronted with a patient with clinically and histologically active EoE, it is prudent to evaluate whether this patient should be treated with an anti-eosinophil drug or with food elimination diet. Since no studies directly comparing the efficacy of these two different modalities have been carried out to date [4], the treatment decision taken is not an evidence-based one and should be based on the individual preference of the patient. Physicians in EoE centers should therefore be adept in treating patients choosing either pharmacological or dietary therapy. Given the fact that currently not one single medication approved for EoE is available on the US and European markets [43••], patients should be carefully instructed on how to administer these drugs, originally designed for the delivery into the airway and not into the esophagus. Indeed, the improper administration of these drugs is believed to be the main cause of refractory EoE [44].

Given the data on efficacy of swallowed topical corticosteroids in bringing active EoE into remission [4], we recommend that EoE patients should be put on an induction treatment with $1 \mathrm{mg}$ bid fluticasone or budesonide for a period of 2 to 4 weeks. Of note, it has been demonstrated that the effect of the compound strongly depends on contact time of the compound with the esophageal surface [45]. Therefore, viscous syrup, melting tablet, or powder are preferable formulations for swallowed topical corticosteroids. Patients should be instructed to avoid eating and drinking for at least half an hour after 
administration of the drug [4]. The best time for application of the drug is at bedtime and after breakfast. A 2-week induction treatment is able to bring approximately $70 \%$ of EoE patients into clinical and histological remission [26].

After achieving a remission, a patient should be put on a maintenance treatment, because if EoE is left untreated, the flare-ups occur after approximately 3 months on average [23, 28]. The long-term regimens are still not well defined. A daily $0.5 \mathrm{mg}$ dose of budesonide might be likely too low for some patients, as approximately one third of the patients had experienced a flare-up episode when being treated with this dose in a 1-year trial [28]. Using doses higher than $2 \mathrm{mg}$ daily has the drawback of lacking safety data regarding systemic side effects. Therefore, the optimal dose might lie somewhere in between 0.5 and $2.0 \mathrm{mg}$. So long that many uncertainties regarding the evolution of the disease and the long-term side effects of pharmacologic treatment still exist, we strongly recommend that EoE patients are seen by a gastroenterologist on an annual basis for clinical, endoscopic, and histologic work-up.

Patients that do not achieve a remission after an induction treatment with swallowed topical corticosteroids need to be reevaluated in order to distinguish between those patients in whom both symptoms and inflammation persist and those in whom only symptoms remain. If inflammation is under control, symptoms might be caused by fibro-stenosis, and a gently performed dilation might be appropriate [46]. In contrast, if inflammation is not under control, either a repeated induction treatment with swallowed topical corticosteroids, a combination of swallowed topical corticosteroids with a single-food elimination diet, or a treatment with immunosuppressants should be considered. However, it is generally recommended to refer patients with refractory EoE to specialized centers. The proposed treatment algorithm is shown in Fig. 1.

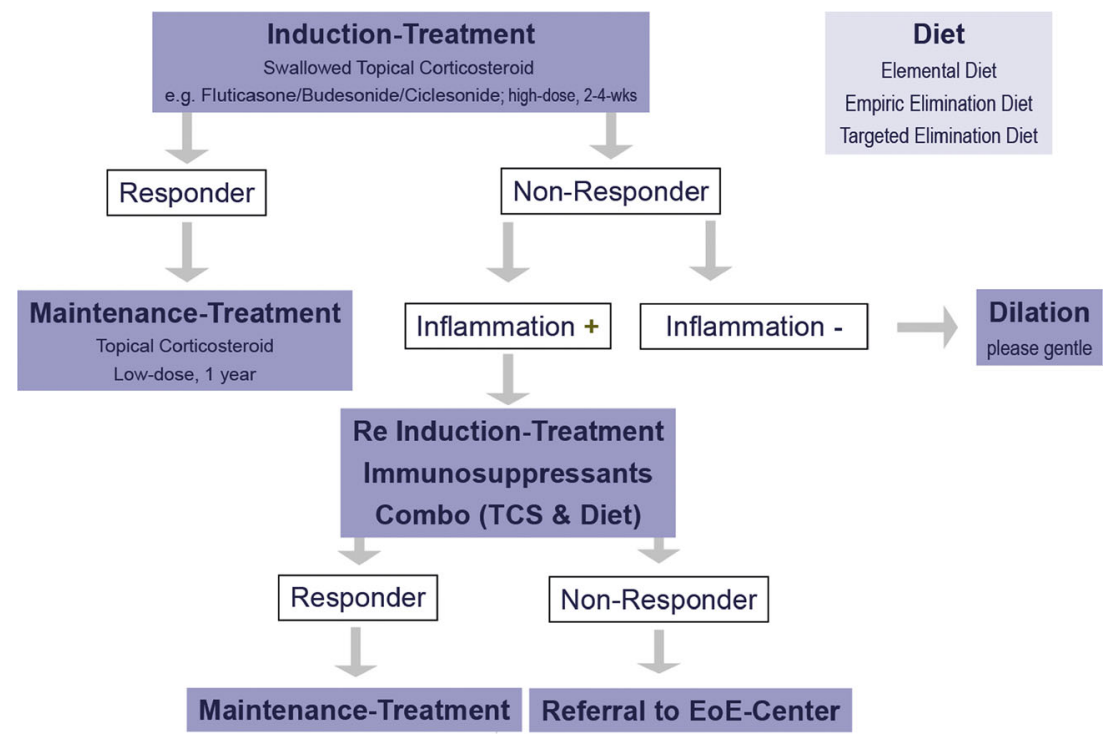

Figure 1. Algorithm illustrating the current treatment strategy in active eosinophilic esophagitis.

Maintenance-Treatment Referral to EoE-Center 


\section{Compliance with Ethics Guidelines}

\section{Conflict of Interest}

Alex Straumann has consultant contracts with Actelion, Buehlmann, Falk, Novartis, Oxagen, Receptos, Regeneron, and Roche-Genentech.

Ekaterina Safroneeva reports the receipt of personal fees from Aptalis Pharma Inc. and from Novartis during the preparation of the paper.

\section{Human and Animal Rights and Informed Consent}

This article does not contain any studies with human or animal subjects performed by the authors.

\section{References and Recommended Reading}

Papers of particular interest, published recently, have been

highlighted as:

- Of importance

-• Of major importance

1. $\quad$ Attwood SE, Smyrk TC, Demeester TR, Jones JB. Esophageal eosinophilia with dysphagia, a distinct clinicopathologic syndrome. Dig Dis Sci. 1993;38:109-16.

First comprehensive description of EoE, recognizing this condition as a distinct entity.

2. Straumann A, Spichtin HP, Bernoulli R, Loosli J, Voegtlin J. Idiopathic eosinophilic esophagitis: a frequently overlooked disease with typical clinical aspects and discrete endoscopic findings [in German with English abstract]. Schweiz Med Wochenschr. 1994;124:1419-29.

3. Furuta GT, Liacouras C, Collins MH, et al. Eosinophilic esophagitis in children and adults: a systematic review and consensus recommendations for diagnosis and treatment. Gastroenterology. 2007;133:1342-63.

4. Liacouras CA, Furuta GT, Hirano I, et al. Eosinophilic esophagitis: updated consensus recommendations for children and adults. J Allergy Clin Immunol. 2011;128:3-20.

5. Straumann A, Aceves SS, Blanchard C, et al. Pediatric and adult eosinophilic esophagitis: similarities and differences. Allergy. 2012;67:477-90.

6. Hruz P, Straumann A, Bussmann C, et al. Escalating incidence of eosinophilic esophagitis: a 20-year prospective, population-based study in Olten County Switzerland. J Allergy Clin Immunol. 2011;128:1349-50.

7. Van Rhijn BD, Verheij J, Smout AJ, et al. Rapidly increasing incidence of eosinophilic esophagitis in a large cohort. Neurogastroenterol Motil. 2013;25:47-52.

8. Straumann A, Spichtin HP, Grize L, Bucher KA, Beglinger C, Simon HU. Natural history of primary eosinophilic esophagitis: a follow-up of 30 adult patients for up to 11.5 years. Gastroenterology. 2003;125:1660-9.

9. Mishra A, Wang M, Pemmaraju VR, et al. Esophageal remodeling develops as a consequence of tissue

10. Aceves SS, Newbury RO, Dohil R, Bastian JF, Broide $\mathrm{DH}$. Esophageal remodeling in pediatric eosinophilic esophagitis. J Allergy Clin Immunol. 2007;119:20612.

11. Lucendo AJ, Arias A, De Rezende LC, et al. Subepithelial collagen deposition, profibrogenic cytokine gene expression, and changes after prolonged fluticasone propionate treatment in adult eosinophilic esophagitis: a prospective study. J Allergy Clin Immunol. 2011;128:1037-46.

12.• Schoepfer AM, Safroneeva E, Bussmann C, et al. Delay in diagnosis of eosinophilic esophagitis increases risk for stricture formation in a time-dependent manner. Gastroenterology. 2013;145:1230-6.

This study clearly demonstrates that active EoE must be treated.

13. Straumann A, Bussmann C, Zuber M, Vannini S, Simon HU, Schoepfer AM. Eosinophilic esophagitis: analysis of food impaction and .perforation in 251 adolescent and adult patients. Clin Gastroenterol Hepatol. 2008;6:598-600.

14 .• Kuchen T, Straumann A, Safroneeva E, et al. Swallowed topical corticosteroids reduce the risk for long-lasting bolus impactions in eosinophilic esophagitis. Allergy. 2014;69:1248-54.

This study demonstrates that the risk of food impaction can be minimized by proper treatment.

15. Straumann A, Safroneeva E, Schoepfer AM. Placebo and other interventions in asthma. N Engl J Med. 2011;365:1446-8.

16. Spechler SJ, Genta RM, Souza RF. Thoughts on the complex relationship between gastroesophageal reflux disease and eosinophilic esophagitis. Am J

Gastroenterol. 2007;102:1301-6.

17. Krarup AL, Villadsen GE, Mejlgaard E, Olesen SS, Drewes AM, Funch-Jensen P. Acid hypersensitivity in 
patients with eosinophilic oesophagitis. Scand J

Gastro. 2010;45:273-81.

18. Ngo P, Furuta GT, Antonioli DA, Fox VL. Eosinophils in the esophagus-peptic or allergic eosinophilic esophagitis? Case series of three patients with esophageal eosinophilia. Amer J Gastroenterology.

2006;101:1666-70.

19.• Molina-Infante J, Ferrando-Lamana L, Ripoll C, et al. Esophageal eosinophilic infiltration responds to proton pump inhibition in most adults. Clin

Gastroenterol Hepatol. 2011;9:110-7.

This is the first study showing that a substantial fraction of EoE responds to PPI.

20. Wen T, Dellon ES, Moawad FJ, Furuta GT, Aceves SS, Rothenberg ME. Transcriptome analysis of proton pump inhibitor-responsive esophageal eosinophilia reveals proton pump inhibitor-reversible allergic inflammation. J Allergy Clin Immunol 2014;e-pub ahead of print.

21. Liacouras CA, Wenner WJ, Brown K, Ruchelli E. Primary eosinophilic esophagitis in children: successful treatment with oral corticosteroids. J Pediatr Gastroenterol Nutr. 1998;26:380-5.

22. Faubion WA, Perrault J, Burgart LJ, Zein NN, Clawson ML, Freese DK. Treatment of eosinophilic esophagitis with inhaled corticosteroids. J Pediatr Gastroenterol Nutr. 1998;27:90-3.

23. Schaefer ET, Fitzgerald JF, Molleston JP, et al. Comparison of oral prednisone and topical fluticasone in the treatment of eosinophilic esophagitis: a randomized trial in children. Clin Gastroenterol Hepatol. 2008;6:165-73.

24. Konikoff MR, Noel RJ, Blanchard C, et al. A randomized, double-blind, placebo-controlled trial of fluticasone propionate for pediatric eosinophilic esophagitis. Gastroenterology. 2006;131:1381-91.

25. Dohil R, Newbury R, Fox L, Bastian J, Aceves S. Oral viscous budesonide is effective in children with eosinophilic esophagitis in a randomized, placebocontrolled trial. Gastroenterology. 2010;139:418-29.

26. Straumann A, Conus S, Degen L, et al. Budesonide is effective in adolescent and adult patients with active eosinophilic esophagitis. Gastroenterology.

2010;139:1526-37.

27. Schroeder S, Fleischer DM, Masterson JC, Gelfand E, Furuta GT, Atkins D. Successful treatment of eosinophilic esophagitis with ciclesonide. J Allergy Clin Immunol. 2012;129:1419-21.

28. Straumann A, Conus S, Degen L, et al. Long-term budesonide maintenance treatment is partially effective for patients with eosinophilic esophagitis. Clin Gastroenterol Hepatol. 2011;9:400-9.

29. Attwood SEA, Lewis CJ, Bronder CS, Morris CD, Armstrong GR, Whittam J. Eosinophilic oesophagitis: a novel treatment using Montelukast. Gut. 2003;52:181-5.

30. Lucendo AJ, De Rezende LC, Jimenez-Contreras S, et al. Montelukast was inefficient in maintaining steroid-induced remission in adult eosinophilic esophagitis. Dig Dis Sci. 2011;56:3551-8.

31. Netzer P, Gschossmann JM, Straumann A, Sendensky A, Weimann R, Schoepfer AM. Corticosteroiddependent eosinophilic oesophagitis: azathioprine and 6-mercaptopurine can induce and maintain longterm remission. Europ J Gastroent Hepatol. 2007;19:865-9.

32. Straumann A, Bauer M, Fischer B, Blaser K, Simon H-U. Idiopathic eosinophilic esophagitis is associated with a $\mathrm{T}_{\mathrm{H}}$ 2-type allergic inflammatory response. J Allergy Clin Immunol. 2001;108:954-61.

33. Straumann A, Hoesli S, Bussmann C, et al. Antieosinophil activity and clinical efficacy of the CRTH2 antagonist OC000459 in eosinophilic esophagitis. Allergy. 2013;68:375-85.

34. Horie S, Gleich GJ, Kita H. Cytokines directly induce degranulation and superoxide production from human eosinophils. J Allergy Clin Immunol. 1996;98:371-81.

35. Straumann A, Conus S, Grzonika P, et al. AntiInterleukin-5 antibody treatment (mepolizumab) in active eosinophilic esophagitis: a randomized, placebo-controlled, double-blind trial. Gut. 2010;59:21-30.

36. Assa'ad AH, Gupta SK, Collins MH, et al. An antibody against IL-5 reduces numbers of esophageal intraepithelial eosinophils in children with eosinophilic esophagitis. Gastroenterology. 2011;141:1593604.

37. Spergel JM, Rothenberg ME, Collins MH, et al. Reslizumab in children and adolescents with eosinophilic esophagitis: results of a double-blind, randomized, placebo-controlled trial. J Allergy Clin Immunol. 2012;129:456-63.

38. Straumann A, Bussmann C, Conus S, Beglinger C, Simon HU. Anti-TNF-alpha (infliximab) therapy for severe adult eosinophilic esophagitis. J Allergy Clin Immunol. 2008;122:425-7.

39. Clayton F, Fang JC, Gleich GJ, et al. Eosinophilic esophagitis in adults is associated with IgG4 and not mediated by IgE. Gastroenterology. 2014;147:602-9.

40. Loizou D, Enav B, Komlodi-Pasztor E, Hider P,KimChang J, Noonan L, Taber T, Kaushal S, Limgala R, Brown M, Gupta R, Balba N, Goker-Alpan O, Khojah A, Alpan $\mathrm{O}$. The effect of omalizumab treatment on allergic tissue inflammation and clinical outcomes in patients with eosinophilic esophagitis; An open label, single arm study. PLOS-One 2014;e-pub ahead of print.

41. Blanchard C, Mingler MK, Vicario M, et al. IL-13 involvement in eosinophilic esophagitis: transcriptome analysis and reversibility with glucocorticoids. J Allergy Clin Immunol. 2007;120:1292-300.

42. Rothenberg ME, Wen T, Greenberg A, Alpan O, Enav B, Hirano I, Nadeau K, Kaiser S, Peters T, Perez A, Jones I, Arm JP, Strieter RM, Sabo R, Gunawardena KA. Intravenous anti-IL-13 mAb QAX576 for the treatment of 
eosinophilic esophagitis. J Allergy Clin Immunol 2014; e-pub ahead of print.

43.• Straumann A, Schoepfer A. Update on basic and clinical aspects of eosinophilic oesophagitis. Gut. 2014;63:1355-63.

This review article provides a good update.

44. Mukkada VA, Furuta GT. Management of refractory eosinophilic esophagitis. Dig Dis. 2014;32:134-8.
45. Dellon ES, Sheikh A, Speck O, et al. Viscous topical is more effective than nebulized steroid therapy for patients with eosinophilic esophagitis. Gastroenterology. 2012;143:321-4.

46. Schoepfer AM, Gonsalves N, Bussmann C, et al.

Esophageal dilation in eosinophilic esophagitis: effectiveness, safety and impact on the underlying inflammation. Amer J Gastroenterol. 2010;105:1062-70. 